\title{
WORK-RELATED STRESS IN THE ITALIAN BANKING POPULATION AND ITS ASSOCIATION WITH RECOVERY EXPERIENCE
}

\section{GABRIELE GIORGI ${ }^{1}$, GIULIO ARCANGELI ${ }^{2}$, ANTONIO ARIZA-MONTES ${ }^{3,4}$, VENERANDO RAPISARDA ${ }^{5}$, and NICOLA MUCCI ${ }^{2}$}

${ }^{1}$ European University of Rome, Rome, Italy

Department of Human Sciences

${ }^{2}$ University of Florence, Florence, Italy

Department of Experimental and Clinical Medicine

${ }^{3}$ University Loyola Andalucía, Cordoba, Spain

Department of Management

${ }^{4}$ Autonomous University of Chile, Santiago, Chile

Department of Business Administration

${ }^{5}$ University of Catania, Catania, Italy

Department of Clinical and Experimental Medicine

\begin{abstract}
Objectives: Over the past decade, there has been a markedly growing interest in issues involving work-related stress in Europe. In Italy, according to Eurofound, research has demonstrated high levels of stress in the banking sector. With this in mind, a study was conducted to evaluate the peculiarities of hindrance and challenge stressors, and their links with recovery in the Italian banking population. Material and Methods: The health and safety managers of a major Italian banking group were contacted and invited to participate in a stress assessment procedure, not only for research purposes but also to help them fulfill their obligations with regard to work-related stress. In total, 6588 bank workers took part in the study $(57.5 \%$ males and $42.5 \%$ females) in 2012-2018. Work-related stress was measured with the Stress Questionnaire (SQ) that assesses several psychosocial working variables. Recovery was measured using a scale based on the SQ. The analysis and tabulation of the study results were performed using the Statistical Package for Social Sciences (SPSS). Results: The results have demonstrated that female respondents lack more job control and colleagues' support as compared to male respondents. Employees aged > 50 lack their supervisors' support while employees with the shortest job seniority experience the greatest role ambiguity, as well as the lack of job control and colleagues' support. The results of hierarchical regression analysis have demonstrated that the lack of colleagues and supervisors' support, as well as job demands and job control, contribute to explaining the recovery experience. The greatest contribution to the explained variance could be attributed to job demands and the lack of colleagues' support. Conclusions: This study has demonstrated an important contribution of the so-called traditional stressors to predicting recovery for the banking population in Italy. These findings suggest that banks should adopt corporate policies containing activities for the prevention of and protection against stress, with a more general objective of improving the mental health of their workers. Int J Occup Med Environ Health. 2019;32(2):255-65
\end{abstract}

Key words:

workplace, occupational stress, occupational medicine, risk assessment, banking, job demand-control model

Received: February 14, 2018. Accepted: August 7, 2018

Corresponding author: Nicola Mucci, University of Florence, Department of Experimental and Clinical Medicine, Largo Piero Palagi 1, I-50139 Florence, Italy (e-mail: nicola.mucci@unifi.it). 


\section{INTRODUCTION}

In recent years, a growing number of empirical investigations, conducted in many countries, have highlighted the negative consequences of work-related stress for workers' health, companies and the society [1-3]. As a result, the issue of work-related stress assessment is nowadays considered in the legislation of many European countries [4,5]. Occupational stress may be considered a product of the dynamic interaction between an individual and the socioorganizational context in which he or she works, constituting the result of a (non-equal) relationship between the stressors related to the task/role and the operator's ability to cope with them [6-9].

The banking sector is experiencing an unprecedented time due to both work organization changes and the global economic crisis [10]. According to the European Foundation for the Improvement of Living and Working Conditions (Eurofound), several surveys have shown that stress is one of the main occupational issues in the banking sector [11]. For several years now, the International Labor Organization (ILO) has highlighted a number of issues concerning workers in the credit sector: greater pressure on time, ergonomics problems, conflicting roles, excessive work demands, complex relationships with customers, and an increasing number of cases of stress and violence [12]. In Italy, the main reason for the reorganization of the credit sector lies in the significant number of mergers and acquisitions. First of all, the growing integration of the domestic banking system with that of the European Union has encouraged the creation of new large companies, able to compete with the main continental banking groups. In addition, remodeling was achieved in banking group alliances, with the consequent acquisition of a dominant position by only three large groups on the domestic market [10,13].

The repercussions of the economic crisis in the banking sector were of 2 types: on the one hand, the progressive reduction in the savings and investment capacity of cus- tomers and, on the other, the increasingly frequent, unforeseen events on the global economic market [14-16]. The Italian National Institute for Insurance against Workplace Accidents and Occupational Diseases (INAIL) and the Independent Federation of Italian Bank Workers (FABI) carried out a survey on health and safety issues among 2100 employees, with a particular focus on training and involvement in health and safety practices. The results revealed that only 1 in 3 respondents felt involved in the health and safety policies implemented by the organization; on the other hand, over two-thirds of respondents reported mental fatigue as a symptom of work pressure [17]. Hence, the issues of health and stress among Italian banking sector employees deserve greater attention from researchers, practitioners and corporate stakeholders.

The main risk factors of occupational stress - as identified by the European Observatory of Working Life - are the following: heavy workload, long working hours, the lack of control and autonomy at work, poor relationships with colleagues, poor support at work, and the impact of organizational change [18]. The literature also shows that high job demands and low job control (e.g., how much discretion people have in their work), as well as role ambiguity, may play a crucial role in work-related stress $[4,18,19]$. All of the above-mentioned factors are known as job stressors in the different models that have been proposed to explain the relationship between working conditions and the negative consequences of stress. For example, one of the most dominant models used to conceptualize stress in organizations is the Job Demand-Control Model by Robert Karasek (1979) [19]. This model integrates 2 main domains: job demands that refer to psychological job demands, such as a high pace and amount of work, and job control (or decision latitude) that refers to autonomy and independence at work [19,20]. Within the financial services sector, there is evidence to support Karasek's model, which associates work-related stress with jobs that 
are highly demanding while simultaneously allowing little control. Many areas of work correspond to this model, whereby individuals have high workloads but relatively little autonomy in completing their assigned tasks [21-23]. Therefore, high job demands and low job control play a role in perceived psychological distress and, as a consequence, the workers who experience a combination of these 2 domains are considered more exposed to occupational stress [24-27].

The major workplace stressors included in the present study can be broken down into 2-dimensional model categories, i.e., hindrance stressors and challenge stressors [28]. Hindrance stressors are stressful demands that are viewed as roadblocks to achieving goals and accomplishments. Challenge stressors are stressful demands that are viewed as potential learning and growth experiences [29]. Types of work-related hindrance stressor are role ambiguity and the lack of support; types of work-related challenge stressor can be ascribed to the dimensions of job demands and job control. Clarke et al. [30] found that although all stressors appear to cause strain - different types of stressors are associated with different affective and behavioral responses. This is one of the reasons why it is important to determine what type of stressors largely affect workers, in such a way as to implement proper coping strategies.

In terms of stress-related outcomes, recovery was highlighted by various researchers [31-35]. Recovery is a process that occurs when the demands (stress factors) imposed on an individual are no longer present [32]. During the recovery process, the functioning of an individual returns to its pre-stressor level, wherein strain is reduced. Thus, recovery can be considered a process opposed to the psycho-physiological activation that occurs under stressful conditions [33]. From a psychological point of view, an individual feels capable and ready to continue with his or her current demands, or to satisfy new demands [34]. From a physiological point of view, Geurts and Sonnentag pre- sented "a conceptual approach to (incomplete) recovery as an explanatory mechanism underlying the relationship between acute physiological stress reactions and chronic health impairment" [35]. In this perspective, recovery is seen as a decrease in physiological strain indicators (e.g., excretion of adrenaline and cortisol or a high heart rate). The aim of this research was to measure the level of workrelated stress in the Italian banking population. Specifically, a survey was conducted on a large sample of employees of a financial group, with the following objectives:

- to identify individual differences (gender, age, job seniority) in work-related stressors among bank workers,

- to test the potential impact of work-related hindrance and challenge stressors on recovery over and above the demographic variables.

The purpose of the research was not only to highlight the issue of work-related stress on a sample of Italian bank employees, but also to provide useful insights into the development of suitable organizational strategies to detect and counteract work-related stress.

\section{MATERIAL AND METHODS \\ Participants}

The authors contacted the health and safety managers of a major Italian banking group and invited them to participate in a stress assessment procedure, not only for research purposes but also to help them fulfill their obligations with regard to work-related stress imposed by Italian regulations on occupational health and safety (Legislative Decree No. 81/2008 [36], as amended). The management of different branches of an Italian banking group agreed to participate in the research and gave their employees the possibility to complete the questionnaires during working hours. In return, each organization received a report to be included in their mandatory Risk Assessment Document. The participating bank branches represented a convenient sample that also reflected a multitude of territorial environments, thus conferring the results with greater validity. 
The questionnaires were administered online through the intranet company portal; anonymity and confidentiality in the responses were fully assured. The participants were informed that the survey was intended to fulfill legal obligations regarding the assessment of work-related stress, with the opportunity to use the findings to improve the quality of their working lives. In this context, the compilation of the survey was very thorough and nearly all of the questionnaires were collected with complete data or with few missing elements that were replaced using the means of the scales.

In total, 6588 Italian bank workers took part in the study: $57.5 \%$ were males and $42.5 \%$ females; $38.7 \%$ were aged $41-50$ (followed by $28.7 \%$ aged $51-60$, and $26.5 \%$ aged 21-30); $42.3 \%$ had held their jobs for 15-30 years (followed by $25.1 \%$ for $8-15$ years, and $22.8 \%$ for $>30$ years). With respect to the territorial area, the sample was conveniently divided across the Italian territory: $41.7 \%$ respondents came from Northern Italy, $41.6 \%$ from Central Italy and Sardinia, and $16.7 \%$ from Southern Italy and Sicily. This subdivision - having value exclusively for the sample description purposes - reflects the organization of the branches in the areas of geographical operations by the banking group.

\section{Measures}

Work-related stress was measured with the Stress Questionnaire (SQ), a tool developed by Giorgi et al. (2012) [37-39]. The Stress Questionnaire assesses several psychosocial working variables related to workrelated stress. The first version of the SQ was based on Karasek's demand-control-support model, and the Health and Safety Executive's Management Standards for workrelated stress $[19,40]$. Based on an analysis of the literature concerning work-related stress, the SQ was further developed, adding emerging stress-related factors and risks, as well as recovery and economic stress (the fear of crisis and non-employability) [36-38]. Furthermore, the critical is- sues experienced in job tasks were considered, also in the physical and psychological contexts. The questionnaire was validated and administered on a big sample of employees [39]. In particular, the validity with the confirmatory factor analysis (CFA) was good and the questionnaire scales were reliable [38,39].

Giorgi et al. [37-39] pointed out that one of the most important aspects of the questionnaire was the psychosocial risk scale; it is based on 5 main psychosocial risks which might lead to negative stress-related outcomes. The scale consists of 25 items and 5 subscales: job demands, job control, role conflict, supervisors' support and colleagues' support. The SQ assesses 5 stress-related factors on a Likert scale ranging from 1 (absolutely agree) to 5 (absolutely disagree):

- role conflict which occurs when employees have no awareness of their roles and responsibilities (5 items; e.g., "I have a clear idea about what is expected of me at work");

- colleagues' support or collaboration and support among employees (5 items; e.g., "I get the support I need from colleagues");

- supervisors' support or the extent to which employees experience support and understanding from their supervisors/leaders (5 items; e.g., "My supervisor energizes me at work");

- job demands which refer to quantitative job demands and job pressure (6 items; e.g., "I have unrealistic deadlines");

- job control or job resources that pertain to the task (5 items; e.g., "I can plan my work").

After recoding the responses to positively worded items, the questionnaire gives a total score, whereby a higher score indicates a greater degree of work-related stress.

Recovery was measured using a 3-item scale from the above-mentioned SQ. A higher score means lower recovery. Demographic aspects were detected by some questions in which information was requested regarding gen- 
der, age, territorial area, job seniority and job position of the respondents.

\section{Statistics}

The analysis and tabulation of the results was performed using the Statistical Package for Social Sciences (SPSS). The following statistical analyses were performed: descriptive statistics, correlations, the 1-way analysis of variance (ANOVA) and hierarchical regression.

First, basic descriptive statistics and $\alpha$ coefficients were calculated. Then, correlations (Pearson's r) were computed between the study variables. The 1-way ANOVA was performed to explore differences among individual groups (e.g., gender, age, job seniority, territorial area). Work-related stress factor scores were used for these analyses.

Hierarchical regression was used to evaluate the relationship between a set of independent variables (role conflict, colleagues' support, supervisors' support, job demands and job control) and a dependent variable, controlling for or taking into account specific demographic variables.

\section{RESULTS}

Descriptive statistics and the results of correlation analysis are depicted in Table 1.
The $\alpha$ reliabilities of the stress factors were satisfactory, indicating good internal consistency. The results of the 1-way analysis of variance demonstrated statistically significant differences between the 2 gender groups as regards the lack of job control $(\mathrm{F}=31.68, \mathrm{df}=1, \mathrm{p}<0.01)$ and the lack of colleagues' support $(\mathrm{F}=20.36, \mathrm{df}=1$, $\mathrm{p}<0.01$ ), with female respondents having greater average values.

There appear to be statistically significant differences (at the 0.01 level) between the 5 age groups as regards the lack of supervisors' support $(\mathrm{F}=5.28, \mathrm{df}=4, \mathrm{p}<0.01)$, job demands $(\mathrm{F}=31.83$, df $=4, \mathrm{p}<0.01)$, the lack of job control $(\mathrm{F}=40.8, \mathrm{df}=4, \mathrm{p}<0.01)$ and role conflict $(\mathrm{F}=8.04, \mathrm{df}=4, \mathrm{p}<0.01)$. In particular, employees $>50$ reported the greatest lack of supervisors' support. The group of respondents aged 31-40 reported greater average values for job demands, the lack of control and role ambiguity. The group $<30$ reported the greatest level of role ambiguity and the lack of job control, along with high values for job demands.

The results indicated significant differences between job seniority groups for all of the factors: role conflict ( $F=10.04, \mathrm{df}=4, \mathrm{p}<0.01)$, the lack of colleagues' support $(\mathrm{F}=4.5, \mathrm{df}=4, \mathrm{p}<0.01)$, the lack of supervisors' support $(\mathrm{F}=3.11, \mathrm{df}=4, \mathrm{p}<0.01)$, job demands $(\mathrm{F}=28.42$,

Table 1. Descriptive statistics and the results of correlation analysis

\begin{tabular}{|c|c|c|c|c|c|c|c|c|c|}
\hline \multirow{2}{*}{ Variables } & \multicolumn{6}{|c|}{ Correlation } & \multirow{2}{*}{ M } & \multirow{2}{*}{ DS } & \multirow{2}{*}{$\alpha$} \\
\hline & 1 & 2 & 3 & 4 & 5 & 6 & & & \\
\hline $\begin{array}{l}\text { 1. Lack of supervisors' } \\
\text { support }\end{array}$ & 1 & $0.253^{* *}$ & $0.342 * *$ & $0.517^{* *}$ & $0.342 * *$ & $0.235^{* *}$ & 2.6019 & 0.85497 & 0.82 \\
\hline 2. Job demands & $0.253^{* *}$ & 1 & $0.511^{* *}$ & $0.345^{* *}$ & $0.095^{* *}$ & $0.654^{* *}$ & 3.2128 & 0.75033 & 0.81 \\
\hline 3. Lack of job control & $0.342 * *$ & $0.511^{* *}$ & 1 & $0.383^{* *}$ & $0.375^{* *}$ & $0.428^{* *}$ & 2.8641 & 0.71913 & 0.77 \\
\hline $\begin{array}{l}\text { 4. Lack of colleagues' } \\
\text { support }\end{array}$ & $0.517^{* *}$ & $0.345^{* *}$ & $0.383^{* *}$ & 1 & $0.289 * *$ & $0.320^{* *}$ & 2.4862 & 0.69813 & 0.79 \\
\hline 5. Role conflict & $0.342 * *$ & $0.095^{* *}$ & $0.375^{* *}$ & $0.289 * *$ & 1 & $0.129^{* *}$ & 2.1355 & 0.68287 & 0.84 \\
\hline 6. Recovery & $0.235^{* *}$ & $0.654^{* *}$ & $0.428^{* *}$ & $0.320^{* *}$ & $0.129^{* *}$ & 1 & 3.3270 & 0.85396 & 0.74 \\
\hline
\end{tabular}

** Correlation is significant at the 0.01 level (2-tailed). 
$\mathrm{df}=4, \mathrm{p}<0.01)$ and the lack of job control $(\mathrm{F}=34.04$, $\mathrm{df}=4, \mathrm{p}<0.01)$. The groups with a job seniority of $16-30$ years and $>30$ years reported greater average values for the lack of supervisors' support. Employees with a job seniority of 3-7 years reported greater average values for the lack of job control and the lack of colleagues' support, as well as high values for role ambiguity and job demand; the group with a job seniority of $<3$ years reported greater average values for role ambiguity and higher values for the lack of job control; the group with a job seniority of $8-15$ years reported higher values for job demands and the lack of colleagues' support.

Finally, the results indicated significant differences between the territorial area groups for all of the factors: role conflict $(\mathrm{F}=11.61$, df $=7, \mathrm{p}<0.01)$, the lack of colleagues' support $(\mathrm{F}=9.79$, $\mathrm{df}=7, \mathrm{p}<0.01)$, the lack of supervisors' support $(\mathrm{F}=4.33$, df $=7, \mathrm{p}<0.01)$, job

Table 2. Results of hierarchical regression analysis (with "recovery" as a criterion variable)

\begin{tabular}{lccc}
\hline \multirow{2}{*}{ Predictors } & \multicolumn{3}{c}{ Recovery } \\
\cline { 2 - 4 } & block 1 & block 2 & block 3 \\
\hline Age & $-0.09^{*}$ & $-0.09^{*}$ & -0.01 \\
Job seniority & 0.01 & $0.01^{*}$ & 0.01 \\
Territorial area & $0.08^{*}$ & 0.07 & $0.04^{*}$ \\
Role conflict & - & 0.02 & 0.01 \\
Lack of colleagues' support & - & $0.26^{* *}$ & $0.07^{*}$ \\
Lack of supervisors' support & - & $0.10^{*}$ & 0.01 \\
Job demands & - & - & $0.57^{* *}$ \\
Lack of job control & - & - & $0.10^{*}$ \\
$\mathrm{R}^{2}$ & 0.01 & 0.12 & 0.45 \\
$\Delta \mathrm{R}^{2}$ & 0.01 & 0.11 & 0.32 \\
\hline
\end{tabular}

${ }^{*} \mathrm{p}<0.05 ; * * \mathrm{p}<0.01$.

$\mathrm{R}^{2}$ - coefficient of determination; $\Delta \mathrm{R}^{2}$ - change in $\mathrm{R}^{2}$ values from one model to another.

The variables tested as predictors in the following blocks: block $1-$ demographics (age, job seniority and territorial area); block 2 - hindrance stressors (role conflict, lack of colleagues' support and lack of supervisors' support); block 3 - challenge stressors (job demands and lack of job control). demands $(\mathrm{F}=14.38, \mathrm{df}=7, \mathrm{p}<0.01)$ and the lack of job $\operatorname{control}(\mathrm{F}=9.11, \mathrm{df}=7, \mathrm{p}<0.01)$.

In addition to the 1-way analysis of variance, the authors performed a hierarchical regression analysis where the total score of "recovery" was used as a dependent variable. Demographic variables (age, job seniority and territorial area) were included in the first block, while hindrance stressors (e.g., role conflict, the lack of colleagues' support and the lack of supervisors' support) were tested in the second block. In the final step, dimensions of the challenge stressor variables (e.g., job demands and the lack of job control) were added. All predictor variables were mean-centered prior to the analyses [41]. Table 2 shows the results of the regression analysis.

The results of hierarchical regression analysis demonstrated that the demographics of age and territorial areas were significant, whereas job seniority was not. As far as the hindrance stressor variables are concerned, both the lack of colleagues' support and the lack of superiors' support were significant, whereas role ambiguity was not significant in predicting the ability to recover. Finally, challenge stressors were associated with the recovery variable and were both significant. Specifically, in the first block, demographic data were significant, except for job seniority. When the hindrance stressor variables were added in the second block, the model was significant, and these dimensions accounted for the $11 \%$ increase in variance (the lack of colleagues' support and the lack of superiors' support). Finally, when the challenge stressor variable dimensions were added in the third block, the model was significant, and these dimensions accounted for the $32 \%$ increase in variance. Overall, the final model of three blocks explains $45 \%$ of the variance for the ability to recover (Table 2).

\section{DISCUSSION}

The purpose of this study was to measure the level of work-related stress in verifying the existence of significant differences in work-related stress factors with respect to 
demographic variables (gender, age, job seniority, territorial area), and to test whether hindrance stressors could explain a significant percentage of incremental variance, compared with both demographic variables and challenge stressors, in explaining the recovery process.

Firstly, the authors compared the differences in stressrelated factors (role conflict, colleagues' support, supervisors' support, job demands and job control) among individual groups, with respect to the following demographic variables: gender, age, job seniority and territorial area. Significant differences were found. Female respondents demonstrated greater average values as regards the lack of job control and the lack of colleagues' support. Previous studies demonstrated contradictory findings regarding work stressors and gender differences. For example, in a study by Spector and Zhou, gender was not significantly linked with perceived organizational support, role ambiguity or overload [42]. In the Pereira et al. study, gender was not significantly linked to social stressors [31]. Li et al. found that psychological capital mediated the relationships of extrinsic effort and reward with emotional exhaustion and depersonalization in males, while in females it partially mediated the relationships of extrinsic effort, reward and over-commitment with emotional exhaustion and depersonalization, as well as the relationship between reward and personal accomplishment [43].

Employees $>50$ appeared to be mostly affected by the impact of the lack of supervisors' support; the group of respondents aged 31-40 years mostly suffered from job demands, whereas the younger group appeared to be mostly affected by the impact of role ambiguity and the lack of job control. Again, previous studies were a bit controversial regarding age differences and workplace stressors. For example, Pereira et al. found no significant links between age and social stressors [31]. Similarly, in a study by $\mathrm{Ku}-$ mar and Sundaram, the variables that included age groups were not found to be significantly associated with the stress level [44]. Stańczak et al., conversely, found a higher proneness to occupational stress among older employees which, in turn, led to higher absenteeism [45].

In this study, when job seniority was taken into account, the results appeared similar to the age group findings: groups with the longest job seniority had higher average values for the lack of supervisors' support; groups with shorter job seniority mostly suffered from role ambiguity and the lack of job control, while the intermediate group was mostly affected by the impact of job demand and the lack of colleagues' support.

The results of the first analysis revealed significant differences with respect to the stressors experienced by bank workers with different demographic characteristics: the elderly were more affected by the lack of support from their supervisors; the younger ones were more stressed by role ambiguity and the lack of job control, as they felt they had no awareness of their roles and responsibilities. Employees with an average length of service were mostly affected by quantitative job demands and job pressure, and by the lack of collaboration and support among employees. In other words, the emerging result was that employees of different age groups, and with different job seniorities, were associated with different stress factors.

Significant differences were observed with respect to gender. Women appeared more stressed than men and this result was in line with international literature. Women suffered more than men from the lack of social support from their colleagues, and from the lack of autonomy and control over their jobs $[41,46,47]$. Psychological capital may be a potentially positive resource in reducing the negative effects of occupational stress on job burnout, and in relieving job burnout among bank employees, especially females [43].

Hierarchical regression demonstrated that both hindrance and challenge stressors explained the variance of recovery. Recovery reflected the extent to which an employee considered him/herself to be unable to fully regain energy in the company where he/she worked, and the extent to 
which he/she felt mentally and physically fatigued. Statistical analyses showed that the demographics of age and territorial areas were significant, whereas job seniority was not. As far as the hindrance stressor variables are concerned, both the lack of colleagues' support and the lack of superiors' support were significant. The contribution of social stressors to poor recovery was previously reported with respect to other samples of employees. For example, Pereira et al. [31] demonstrated that social stressors contributed to poorer recovery. Interestingly, challenge stressors added in the third block explained the greatest amount of variance, i.e., they accounted for the additional $32 \%$ of the increased explained variance. Job demands were the most important predictor $(\beta=0.572)$. Although, job demands were claimed to be a challenge stressor that might put an individual in a stressful, but motivating, state, it does seem that they have an important contribution to explaining recovery challenges [48]. Some previous studies support the findings of this study. For example, Sonnentag and Fritz claimed, in particular, that workload might predict challenges in psychological detachment [49].

In summary, the present study demonstrated an important contribution of the so-called traditional stressors to predicting recovery for the banking population in Italy. Overall, the model explained $45 \%$ of the variance of recovery, which is a large proportion.

Some limitations of the present study have to be addressed. The first limitation is that it cannot prove causality since the study design was cross-sectional. Consequently, the use of a longitudinal design is suggested. The second limitation is the use of self-reports, which may contribute to common method bias. The third limitation concerns the sample which is not representative of the Italian population; in addition, the bank agencies included in the study belong to the same parent company and, consequently, the variance between groups was not considered. The fourth limitation consists in having used a short recovery scale for the convenience of the study (a shortage of items), instead of a complete scale such as, for example, the Recovery Experience Questionnaire (REQ) [50].

In addition, the authors could not statistically analyze the differences related to the division into territorial areas for the following reasons: sample homogeneity, features in the composition of each area (e.g., the coexistence of continental and island territories), differences in the type of organization and the autonomy of the organizational processes of each peripheral branch from the area leader branch. However, from a descriptive point of view, the authors noticed that bankers from the central and southern regions of Italy reported higher stress indices. This observation may denote the importance of socio-cultural factors in the perception of work-related stress. With this in mind, the authors feel the need to carry out future studies on this topic.

\section{CONCLUSIONS}

The findings of this study suggest that banks should adopt corporate policies containing activities for the prevention of and protection against stress. These strategies have a dual objective of protecting workers' mental health and containing company costs for the management of workrelated stress [51].

In particular, banks should pay careful attention to problems associated with the following stress factors which gradually build up and, if not dealt with early enough, could have a domino effect on both individuals and the organization: work overload; organizational role (responsibility, ambiguity); working conditions; individual differences and needs; and relationships at work.

The present study pointed out a number of individual and organizational characteristics that may be important for preventing and reducing the incidence of work-related stress in the Italian banking population. In particular, the results of the study suggest that organizational programs that take individual characteristics (especially age, gender and job seniority) into consideration may also be impor- 
tant in preventing work-related stress. For example, supervisor training could be important for reducing the main stress factor reported by workers $>50$, who complained about the lack of support from their supervisors. Providing supervisors with the necessary skills and information on the difficulties these workers are currently experiencing might have a favorable effect on both individuals and teams.

Similarly, it should be borne in mind that younger workers sometimes have little awareness of their roles and responsibilities. In such a context, an active and proactive role of older workers can be very important in laying the foundations for a "generational pact" that should be facilitated through appropriate corporate policies. An effective "generational pact" should be implemented by taking into consideration the identification of high priority populations, and by developing training programs with a focus on individual and group coping strategies.

\section{REFERENCES}

1. Gilboa S, Shirom A, Fried Y, Cooper C. A meta-analysis of work demand stressors and job performance: Examining main and moderating effects. Pers Psychol. 2008;61(2):22771, https://doi.org/10.1111/j.1744-6570.2008.00113.x.

2. Van Bogaert P, Peremans L, van Heusden D, Verspuy M, Kureckova V, van de Cruys Z, et al. Predictors of burnout, work engagement and nurse reported job outcomes and quality of care: A mixed method study. BMC Nurs. 2017;16(1):5, https:// doi.org/10.1186/s12912-016-0200-4.

3. Astrauskaite M, Notelaers G, Medisauskaite A, Kern R. Workplace harassment: Deterring role of transformational leadership and core job characteristics. Scand J Manag. 2015;31(1):121-35, https://doi.org/10.1016/j.scaman.2014. 06.001 .

4. Fishta A, Backé E. Psychosocial stress at work and cardiovascular diseases: An overview of systematic reviews. Int Arch Occup Environ Health. 2015;88(8):997-1014, https://doi. org/10.1007/s00420-015-1019-0.
5. Krishnamurthy M, Ramalingam P, Perumal K, Kamalakannan LP, Chinnadurai J, Shanmugam R, et al. Occupational heat stress impacts on health and productivity in a steel industry in Southern India. Saf Health Work. 2017;8(1):99104, https://doi.org/10.1016/j.shaw.2016.08.005.

6. Brough P, Drummond S, Biggs A. Job support, coping, and control: Assessment of simultaneous impacts within the occupational stress process. J Occup Health Psychol. 2018;23(2)188-97, https://doi.org/10.1037/ocp0000074.

7. Jacobs S, Johnson S, Hassell K. Managing workplace stress in community pharmacy organisations: Lessons from a review of the wider stress management and prevention literature. Int J Pharm Pract. 2018;26(1):28-38, https://doi.org/10.1111/ijpp.12360.

8. Eddy P, Heckenberg R, Wertheim E, Kent S, Wright B. A systematic review and meta-analysis of the effort-reward imbalance model of workplace stress with indicators of immune function. J Psychosom Res. 2016;91:1-8, https://doi. org/10.1016/j.jpsychores.2016.10.003.

9. Siegrist J, Li J. Associations of extrinsic and intrinsic components of work stress with health: A systematic review of evidence on the effort-reward imbalance model. Int J Environ Res Public Health. 2016;13(4):432, https://doi.org/10.3390/ ijerph13040432.

10. Giorgi G, Arcangeli G, Perminiene M, Lorini C, Ariza-Montes A, Fiz-Perez J, et al. Work-related stress in the banking sector: A review of incidence, correlated factors, and major consequences. Front Psychol. 2017;8:2166, https://doi. org/10.3389/fpsyg.2017.02166.

11. Anderson R, Mikuliç B, Vermeylen G, Lyly-Yrjanainen M, Zigante V. Second European Quality of Life Survey - Overview. Luxembourg: Office for Official Publications of the European Communities; 2009.

12. Giga SI, Hoel H. Violence and stress at work in financial services. Geneva: International Labor Office; 2003.

13. Pohl M, Tortella T. A century of banking consolidation in Europe: The history and archives of mergers and acquisitions. Abingdon-on-Thames: Routledge; 2017, https://doi. org/10.4324/9781315264028. 
14. Dom G, Samochowiec J, Evans-Lacko S, Wahlbeck K, van Hal G, McDaid D. The impact of the 2008 economic crisis on substance use patterns in the countries of the European Union. Int J Environ Res Public Health. 2016;13(1):122, https://doi.org/10.3390/ijerph13010122.

15. Frasquilho D, Matos MG, Salonna F, Guerreiro D, Storti CC, Gaspar T, et al. Mental health outcomes in times of economic recession: A systematic literature review. BMC Public Health. 2016;16:115, https://doi.org/10.1186/s12889-016-2720-y.

16. Van Hal G. The true cost of the economic crisis on psychological well-being: A review. Psychol Res Behav Manag. 2015;8:17-25, https://doi.org/10.2147/PRBM.S44732.

17. Macciocu L, Nardella C, Rossi I, Stella, M, Brizio L. [The active participation of the worker in the prevention of psychosocial risks in the credit sector: a priority element for the implementation of a socially responsible company]. Prevention Today. 2008;4(2):17-40.

18. Broughton A. Work-related stress. Luxembourg: Office for Official Publications of the European Communities; 2010.

19. Karasek R. Job demands, job decision latitude, and mental strain: Implications for job redesign. Adm Sci Q. 1979;24(2):285, https://doi.org/10.2307/2392498.

20. Karasek R, Theorell T. Healthy work. New York: Basic Books; 2010.

21. Hoert J, Herd A, Hambrick M. The role of leadership support for health promotion in employee wellness program participation, perceived job stress, and health behaviors. Am J Health Promot. 2016:089011711667779, https://doi. org/10.1177/0890117116677798.

22. Lee BX, Donnelly PD, Cohen L, Garg S. Violence, health, and the 2030 agenda: Merging evidence and implementation. J Public Health Policy. 2016;37(S1):1-12, https://doi. org/10.1057/s41271-016-0011-6.

23. Kan D, Yu X. Occupational stress, work-family conflict and depressive symptoms among Chinese bank employees: The role of psychological capital. Int J Environ Res Public Health. 2016;13(1):134, https://doi.org/10.3390/ijerph1 3010134.
24. Valente M, Menezes P, Pastor-Valero M, Lopes C. Re: Response to "Depressive symptoms and psychosocial aspects of work in bank employees" Occup Med (Lond). 2016;66(5):421-2, https://doi.org/10.1093/occmed/kqw058.

25. Petarli GB, Zandonade E, Salaroli LB, Bissoli NS. Assessment of occupational stress and associated factors among bank employees in Vitoria, State of Espírito Santo, Brazil. Cien Saude Colet. 2015;20(12):3925-34, https://doi.org/ 10.1590/1413-812320152012.01522015.

26. Snorradóttir Á, Vilhjálmsson R, Rafnsdóttir G, Tómasson K. Financial crisis and collapsed banks: Psychological distress and work related factors among surviving employees - A nation-wide study. Am J Ind Med. 2013;56(9):1095-106, https://doi.org/10.1002/ajim.22210.

27. Sakuraya A, Shimazu A, Eguchi H, Kamiyama K, Hara Y, Namba K, et al. Job crafting, work engagement, and psychological distress among Japanese employees: A crosssectional study. Biopsychosoc Med. 2017;11(1):6, https://doi. org/10.1186/s13030-017-0091-y.

28. Selye H. Forty years of stress research: Principal remaining problems and misconceptions. Can Med Assoc J. 1976;115(1):53-6.

29. Cavanaugh M, Boswell W, Roehling M, Boudreau J. An empirical examination of self-reported work stress among U.S. managers. J Appl Psychol. 2000;85(1):65-74, https://doi. org/10.1037/0021-9010.85.1.65.

30. Clarke S. The effect of challenge and hindrance stressors on safety behavior and safety outcomes: A meta-analysis. J Occup Health Psychol. 2012;17(4):387-97, https://doi.org/ 10.1037/a0029817.

31. Pereira D, Gross S, Elfering A. Social stressors at work, sleep, and recovery. Appl Psychophysiol Biofeedback. 2015;41(1): 93-101, https://doi.org/10.1007/s10484-015-9317-6.

32. Bakker AB, Demerouti E. The Job Demands-Resources model: State of the art. J Manage Psychol. 2007;22(3):30928, https://doi.org/10.1108/02683940710733115.

33. Sonnentag S, Natter E. Flight attendants' daily recovery from work: Is there no place like home? Int J Stress 
Manag. 2004;11(4):366-91, https://doi.org/10.1037/1072-5245. 11.4.366.

34. Zijlstra FRH, Sonnentag S. After work is done: Psychological perspectives on recovery from work. Eur J Work Organ Psychol. 2006;15(2):129-38, https://doi.org/10.1080/ 13594320500513855.

35. Geurts S, Sonnentag S. Recovery as an explanatory mechanism in the relation between acute stress reactions and chronic health impairment. Scand J Work Environ Health. 2006;32(6):482-92, https://doi.org/10.5271/sjweh.1053.

36. Testo unico sulla salute e sicurezza sul lavoro. D.lgs. 9 aprile 2008, n. 81. Testo coordinato con il D.Lgs. 3 agosto 2009, n. 106. Italian.

37. Giorgi G, Arcangeli G, Cupelli V. [Work-related stress Leaders and collaborators compared]. Naples: Edises; 2012.

38. Giorgi G, Arcangeli G, Cupelli V. SQ - Stress Questionnaire. Florence: Hogrefe; 2013.

39. Mucci N, Giorgi G, Cupelli V, Gioffrè PA, Rosati MV, Tomei F, et al. Work-related stress assessment in a population of Italian workers. The Stress Questionnaire. Sci Total Environ. 2015;502:673-9, https://doi.org/10.1016/j.scitotenv.2014.09.069.

40. Edwards JA, Webster S, van Laar D, Easton S. Psychometric analysis of the UK Health and Safety Executive's Management standards work-related stress indicator tool. Work Stress. 2008;22(2):96-107, https://doi.org/10.1080/ 02678370802166599.

41. Amigo I, Asensio E, Menéndez I, Redondo S, Ledesma JA. Working in direct contact with the public as a predictor of burnout in the banking sector. Psicothema. 2014;26(2):2226, https://doi.org/10.7334/psicothema2013.282.

42. Spector P, Zhou Z. The moderating role of gender in relationships of stressors and personality with counterproductive work behavior. J Bus Psychol. 2013;29(4):669-81, https://doi. org/10.1007/s10869-013-9307-8.

43. Li X, Kan D, Liu L, Shi M, Wang Y, Yang X, et al. The mediating role of psychological capital on the association between occupational stress and job burnout among bank employees in China. Int J Environ Res Public Health. 2015;12(3):29843001, https://doi.org/10.3390/ijerph120302984.

44. Kumar SG, Sundaram ND. Prevalence of stress level among bank employees in urban Puducherry, India. Ind Psychiatry J. 2014;23(1):15-7, https://doi.org/10.4103/09726748.144938.

45. Stańczak A, Mościcka-Teske A, Merecz-Kot D. [Psychosocial risks and the job activity of banking sector employees]. Med Pr. 2014;65(4):507-19, https://doi.org/10.13075/ mp.5893.00055. Polish.

46. Fernandes C, Mekoth N, Kumar S, George B. Organisational role stress and the function of selected organisational practices in reducing it: Empirical evidence from the banking service front line in India. Int J Behav Healthc Res. 2012;3(3/4):258, https://doi.org/10.1504/ijbhr.2012.051392.

47. Arcangeli G, Giorgi G, Ferrero C, Mucci N, Cupelli V. [Prevalence of workplace bullying in a population of nurses at three Italian hospitals]. G Ital Med Lav Ergon. 2014;36(3): $181-5$.

48. Karasek R, Baker D, Marxer F, Ahlbom A, Theorell T. Job decision latitude, job demands, and cardiovascular disease: A prospective study of Swedish men. Am J Public Health. 1981;71(7):694-705, https://doi.org/10.2105/ajph.71.7.694.

49. Sonnentag S, Fritz C. Recovery from job stress: The stressordetachment model as an integrative framework. J Occup Behav. 2014;36(S1):S72-103, https://doi.org/10.1002/job.1924.

50. Sonnentag S, Fritz C. The Recovery Experience Questionnaire: Development and validation of a measure for assessing recuperation and unwinding from work. J Occup Health Psychol. 2007;12(3):204-21, https://doi.org/10.1037/1076-8998. 12.3.204.

51. Hassard J, Teoh KRH, Visockaite G, Dewe P, Cox T. The cost of work-related stress to society: A systematic review. J Occup Health Psychol. 2018;23(1):1-17, https://doi. org/10.1037/ocp0000069.

This work is available in Open Access model and licensed under a Creative Commons Attribution-NonCommercial 3.0 Poland License - http://creativecommons.org/ licenses/by-nc/3.0/pl/deed.en. 